Conference Paper

\title{
Detection of Micronucleus, Nucleoplasmic Bridges, and Nuclear Buds Frequency in Peripheral Blood Lymphocytes of Cancer Patient Post-Radiation Fractionated
}

\author{
Teja Kisnanto ${ }^{*}$, Yanti Lusiyanti1 ${ }^{1}$, Dyah Erawati², Suryadi ${ }^{1}$ \\ ${ }^{1}$ Center for Technology of Radiation Safety and Metrology, National Nuclear Energy Agency \\ (PTKMR-BATAN), Jakarta 12070, Indonesia \\ ${ }^{2}$ Departement of Radiotherapy, dr. Soetomo General Academic Hospital, Surabaya 60286, Indonesia
}

*Corresponding author:

E-mail: kisnanto@batan.go.id

\begin{abstract}
Simple measurement of cytogenetic damage would be of great value for studying genetic risk factors, especially in radiotherapy for cancer patients. One cytogenetic technique that is easy and simple to quantify the damage caused by radiation exposure in cultured human lymphocytes is the micronucleus (MN). This research was conducted to study the induction of micronucleus (MN), Nucleoplasmic Bridge (NPB), and Nuclear Buds (NBUDs) in cancer patients after administration of fractionated radiation exposure total of $20 \mathrm{~Gy}$. Peripheral blood lymphocyte samples obtained from eleven cancer patients as the study group and eleven from the healthy people as the control group were assessed. Both samples were then cultured and added cytochalasin-B to arrest cells during the cytokinesis stage. Its characteristics were observed in binucleated cells (BNC) with cytochalasin blocked micronuclei (CBMN) assay procedure. The number of MN, NPB, and NBUDs was evaluated per $1000 \mathrm{BNC}$ for both the study group and control. The results showed that there was a statistically signif- icant difference $(\mathrm{P}<0.05)$ between the frequency of $\mathrm{MN}$ in the study group $(82.18 \pm 39.93)$ compared to controls $(13.18 \pm 4.94)$. Besides, the number of NPB and NBUD in the study group is relatively low. In conclusion, the iden- tification of MN formation in peripheral blood lymphocytes of post-radiation cancer patients has other molecular mechanisms such as NPB and NBUD. Also, demographic factors such as age can influence the appearance of MN, NPB, and NBUDs.
\end{abstract}

\section{Introduction}

Genome instability and changes in the structure and number of chromosomes are significant alterations that lead to cancer (Iarmarcovai et al., 2008). The cellular process in multicellular organisms is a complex interaction to maintain genome stability and settle the state of cell homeostasis and sustainable genetic inheritance. However, both endogenous and exogenous exposure to the genome affects structural transformation in the chromosomes, leading to dose and gene expression changes. Mutations in oncogenes, tumor suppressor genes, and other genes bound in genome maintenance could induce mutator phenotypes that upgrade the risk of achieving new transformations, including those linked to cancer (Bonassi et al., 2011; Keen- Kim et al., 2008).

The susceptibility of individuals to cancer cells can be affected by several factors, including environmental exposure and genetic factors. Therefore, this difference in individuals' susceptibility is a challenge in quantitative cancer risk assessment and requires accurate testing and validation

\section{How to cite:}

Kisnanto, T., Lusiyanti, Y., Erawati, D., \& Suryadi. (2021). Detection of micronucleus, nucleoplasmic bridges, and nuclear buds frequency in peripheral blood lymphocytes of cancer patient post-radiation fractionated. $1^{s t}$ Bioinformatics and Biodiversity Conference. NST Proceedings. pages 45-51. doi: 10.11594/ nstp.2021.0707 
of high-risk individual biomarkers. Cytogenetic biomarkers have proven to have a positive correlation with cancer risk in humans, where chromosomal aberration is a relevant marker for cancer risk (Pardini et al., 2017).

In recent decades, various types of in vitro and in vivo genotoxicity have been performed very well. Cytogenetic methods are essential for detecting DNA damage due to environmental exposure, chemical induction, and ionizing radiation (Sommer, 2020). Although different DNA damage repair systems process the DNA damage caused by IR, its improper repair can lead to cell death or the formation of mutagenic lesions of varying complexity (Ye et al., 2019). Ionizing radiation can create various DNA damage forms, including increased frequency of chromosome aberrations and micronucleus (MN). One cytogenetic technique that is easyand simple to quantify the damage caused by radiation exposure in cultured human lymphocytes is MN (Fenecht et al., 1990). MN with the cytokinesis-block micronucleus (CBMN) assay is a superior, validated, standard technique for assessing radiation exposure in individuals exposed to ionizing radiation and determining radiosensitivity of cancer susceptibility in vitro (Lusiyanti et al., 2016; Lusiyanti et al., 2017). Micronuclei form during the cell's mitotic division and contain whole chromosomal or acentric chromosomal fragments that are not incorporated into the cell nucleus (Özdal et al., 2016).

Several mechanisms can ensue in forming MN, such as nucleoplasmic bridges (NPB) and nuclear buds (NBUD). NPB initiated with the breaking of the double strand of DNA (DSB) in one chromosome. The formation of NPB occurs when the centromere of the dicentric chromatids moves towards the opposite poles during the anaphase process to form a long thread connecting the two nuclei. In contrast, the acentric chromatid fragments are left behind and create MN. Meanwhile, NBUD occurs due to chromosomal bridge damage during the telophase stage. NBUD is characterized by having the same morphology as MN except that NBUD is connected to the nucleus by the nucleoplasm depending on budding location (Fenech et al., 2011; Lindberg et al., 2007).

The present study was conducted to study the frequency of micronucleus (MN), Nucleoplasmic Bridge (NPB), and Nuclear Buds (NBUDs) in cancer patients after administration of fractionated radiation exposure of $20 \mathrm{~Gy}$.

\section{Material and Methods \\ Ethics}

The study was approved by the Ethics Committee Review Board at the National Health Research Institute, Ministry of Health of the Republic of Indonesia in Jakarta with number LB.02.01/5.2.KE.051/2016 (dated January 29, 2016). Respondents have filled in informed consent and obtained explanations related to research procedures.

\section{Subject and blood sampling}

As the study group, eleven cancer patients had been given external radiation exposure with a fractionation dose of $20 \mathrm{~Gy}$ in the Radiology and Radiotherapy installation at dr. Soetomo Hospital, Surabaya, Indonesia. Meanwhile, the control group was eleven non-cancer participants who had never been exposed to ionizing radiation. Peripheral blood samples were taken by venipuncture using heparinized vacutainer tubes. Two vacutainer tubes were obtained from each sample. Blood samples were taken to the Molecular Radiobiology laboratory, Center for Technology of Radiation Safety and Metrology, National Nuclear Energy Agency, Jakarta for advanced analysis.

\section{Culture and harvesting for $M N$}

The MN procedure refers to the MN assay protocol of the International Atomic Energy Agency (IAEA) publication with minor modifications (IAEA, 2011). Whole blood samples were cultured for $72 \mathrm{~h}$ in an incubator at $37^{\circ} \mathrm{C}$ containing $5 \% \mathrm{CO}_{2}$. The culture medium consisted of $4.5 \mathrm{~mL}$ of Rosewell Park Memorial Institute (RPMI) 1640 supplemented with 20\% heat-inactivated fetal bovine serum (FBS), 2\% penicillin-streptomycin, 2\% phytohemagglutinin (PHA).At $44 \mathrm{~h}$ incubated, 
$15 \mu \mathrm{L}$ of Cytochalasin-B was added to the culture. The cells were then centrif- ugated for 10 mins at $800 \mathrm{rpm}$ and resuspended in $7 \mathrm{~mL}$ of $0.075 \mathrm{M}$ cold $\left(4^{\circ} \mathrm{C}\right) \mathrm{KCl}$. Afterward, the cells were centrifugated once more for eight minutes at $800 \mathrm{rpm}$ and resuspended in freshly made fixative consisting of methanol: acetic acid (10:1) diluted 1:1 with Ringer's solution. The cells were then washed with two to three further changes of freshly methanol: acetic acid (10:1) without Ringer's resolution until the cell suspension was apparent. Fixed cells were dropped onto slides and then dried and stained with $4 \%$ Giemsa solution (pH 6,8) for 10 mins. The parameters of MN, NPB, and NBUD were determined at a magnification of $1000 x$ for each sample. Specifically, for MN, variations in MN forms such as MN 1, MN 2, MN 3, MN 4, and MN 5 were also observed (Figure 1).

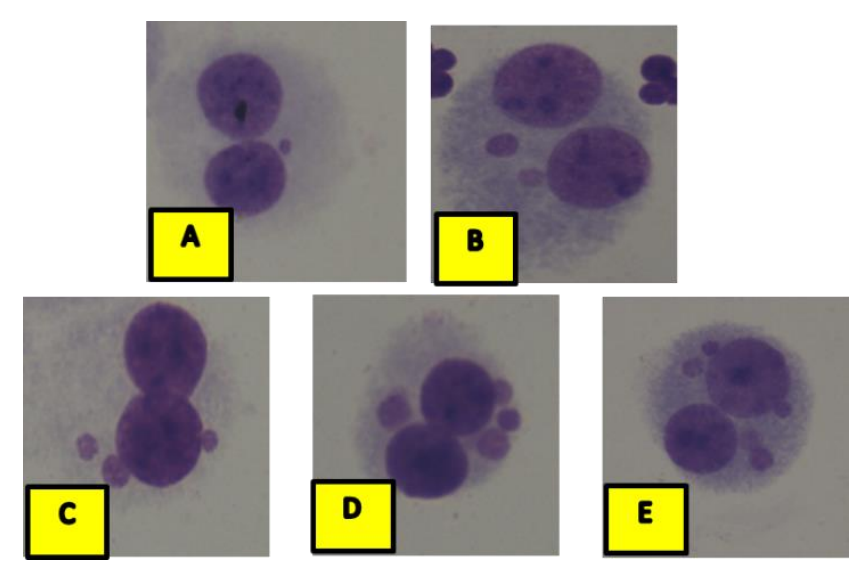

Figure 1. Shapes of MN 1, MN 2, MN 3, MN 4, and MN 5 at 1000x magnification

\section{Statistical analysis}

The data were analyzed using IBM SPSS Statistics 24.0 software. The data analysis was continued by ANOVA following by an ad hoc test if the data were normally distributed. If, however, data were not normally distributed even after transformation, the nonparametric analysis was performed.

\section{Results and Discussion Evaluation of $M N$}

In the study, the identification of $\mathrm{MN}$ frequencies was calculated by observing 1000 binucleate cells (BNC) for each sample, both study, and control groups. The results showed that the frequency of MN in the study group ranged from 44 to 183. Meanwhile, the control group ranged from 4 to 21. Refers to the IAEA guidelines (2011), ordinary individuals have $M N$ frequencies ranging from 3 to 30 (IAEA, 2011). Statistical analysis showed a significant difference between the frequency of MN in the study group (82.18 \pm 39.93$)$ compared to the control group (13.18 \pm 4.94$)$ (Fig. 2). The data indicated that the frequency of MN in the study group is almost seven times higher than in the control group. A study conducted by Ozdal et al. (2016) concluded that cancer patients who were given radiation exposure would have a higher MN frequency than those without radiation. Besides, an increase in the frequency of MN was closely related to the rise in the dose of exposure (Fenecht et al., 1990; Özdal et al., 2016). Theoretically, MN formation due to ionizing radiation ranges from less than 1 Gy to more than 4 Gy (IAEA, 2011). 


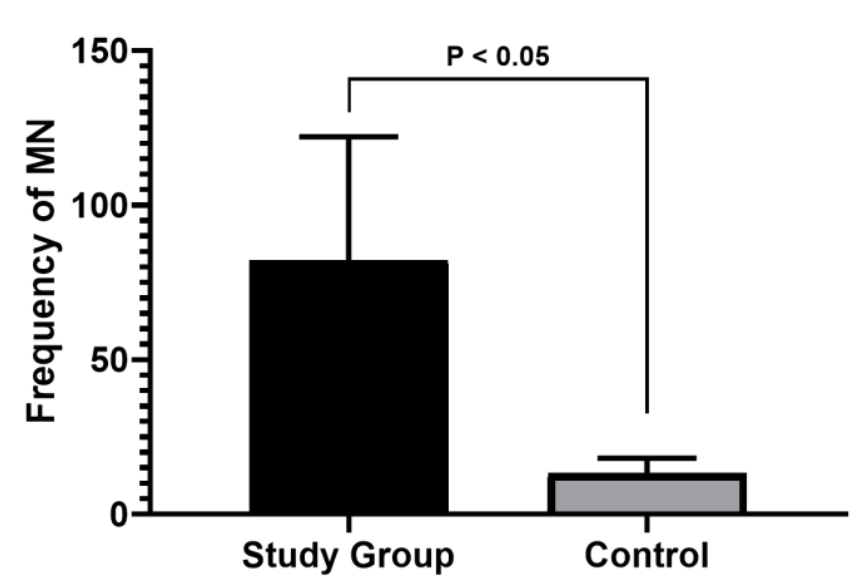

Figure 2. Comparison of the frequency of MN in the study and control groups

Suppose it is reviewed based on the distribution data of MN formation in the study group, as shown in Fig. 3. In that case, it shows that all patients have the most extensive distribution of MN in BNC containing MN 1, then followed by BNC containing MN 2. Meanwhile, not all patients have BNC containing MN 3, MN 4, and MN 5. The number of MN in each patient is closely related to the severity of chromosomal damage that occurs. Exposure to ionizing radiation will cause chromosomal abnormalities during anaphase and metaphase. The deviation applies especially to unstable chromosomes that will experience damage or mutation, which is also the leading cause of $\mathrm{MN}$ formation (Sommer et al., 2020; Ye et al., 2019).

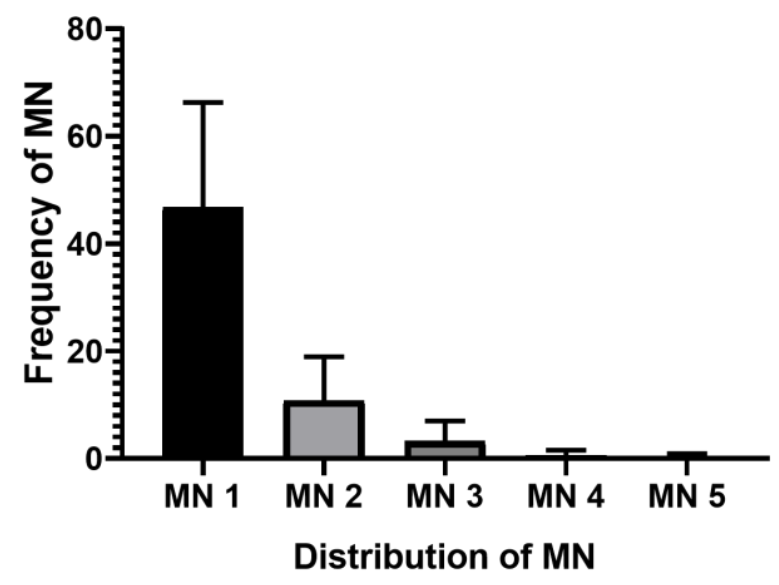

Figure 3. Distribution of MN per 1000 BNC in Study Group

Factors that influence the formation of MN include age, gender, nutritional status, diet, lifestyle (smoking, alcohol consumption), genotype, and chronic illness (Battershill et al., 2008; Ye et al., 2019). Besides, the phenomenon of varying MN frequencies is also caused by the immune response and DNA repair ability for each individual to be different and depending on the type of cancer suffered (Özdal et al., 2016; Palyvoda et al., 2003). Based on the correlation test results between the frequency of MN and age in the study group (Fig. 4), it was stated that there was a very weak negative correlation $(\mathrm{R} 2=0.0753)$ where the frequency of MN did not depend on the in- 
creasing age of the individual. The study contrasts with several previous studies that showed increasing age would increase the frequency of MN (Battershill et al., 2008). As individuals age, there would be an increase in the number of mutations or chromosomal aberrations in MN formation caused by genomic instability. It is understood as a cytogenetic study that can be detected as an increase in the number of changes in chromosome structure. Genomic instability reflects a decreased ability of cells to repair DNA damage (Battershill et al., 2008; Fenech \& Bonassi, 2011; Narendran et al., 2019). Therefore, further investigation is needed regarding MN frequency on age, especially in cancer patients who have been irradiated with a more representative sample size.

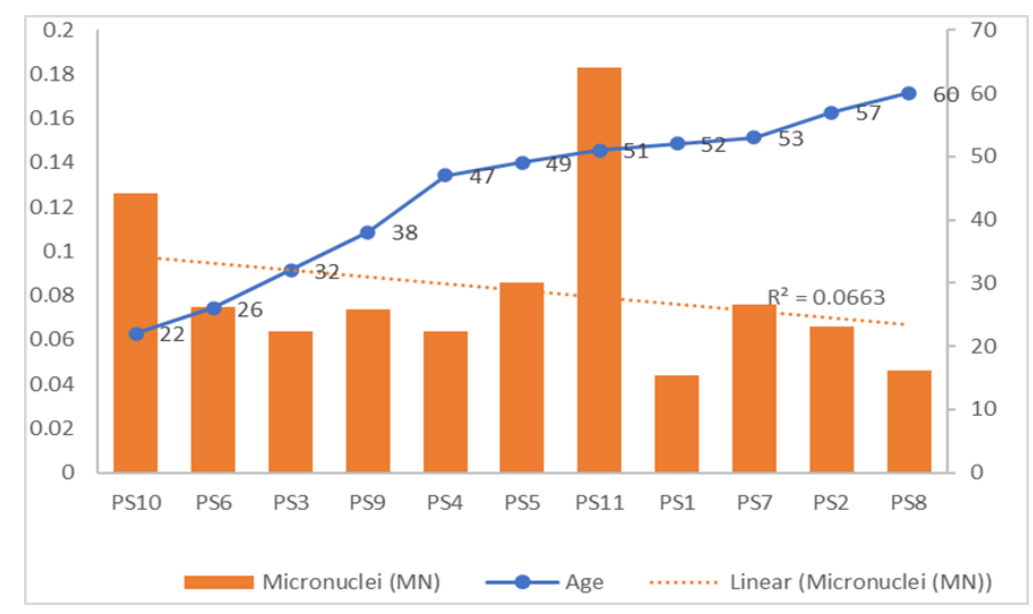

Figure 4. Correlation between age and MN formation in Study Group

\section{Evaluation of NPB and NBUD}

In addition to identifying $\mathrm{MN}$ formation, this study also examines the construction of a nucleoplasmic bridge (NPB) and nuclear buds (NBUDs). Fig.5 shows that cancer patients who have been exposed to external radiation with a fractionation of $20 \mathrm{~Gy}$ indicate that the number of NPB and NBUD is relatively low and not found in all patients. Apart from ionizing radiation, many factors cause the formation of NPB in blood cells, including polycyclic aromatic hydrocarbons, cigarette smoke, folate, and selenium deficiency (Fenech \& Bonassi, 2011). Meanwhile, only a few NBUD phenomena were found during the observation, and this requires further research to determine the factors and mechanisms that occur with the molecular assay. NBUDs is less common than micronuclei in many cell types (Anbumani \& Mohankumar, 2015; Lindberg et al., 2007).

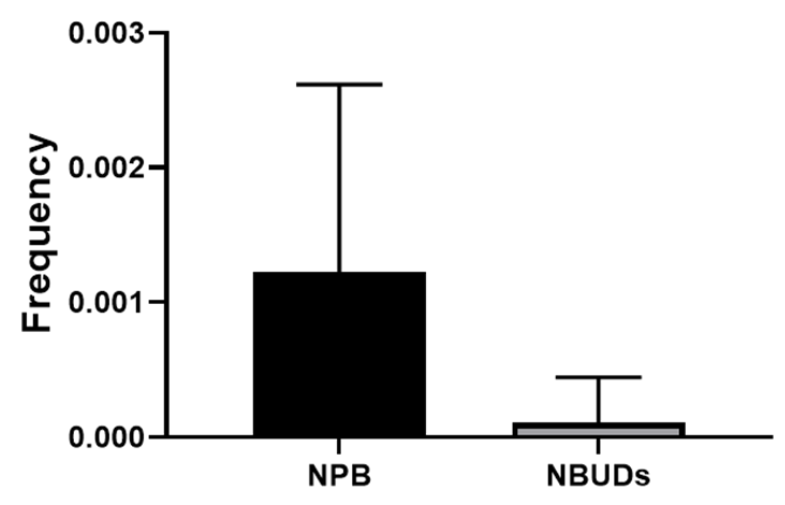

Figure 5. Mean frequency of NPB and NBUDs in Study Group 
The association between the frequency of MN, NPB, and NBUD and the development of benign and malignant tumors has been reported in other studies. The report shows an increase in these biomarkers' frequency in patients with various types of lesions and healthy relatives of cancer patients (Fenech et al., 2011; Gashi et al., 2018). MN, NPB, and NBUD are nuclear anomalies commonly seen in cancer and represent general phenotypes of chromosomal instability. This event will cause changes in the dose of genes and the potential for cells to proliferate and mutate due to genetic plasticity and abnormal genotypes controlled by the homeostatic mechanisms. (Fenech \& Bonassi, 2011).

\section{Conclusion}

Identifying MN formation in peripheral blood lymphocytes of post-radiation cancer patients has other molecular mechanisms such as NPB and NBUDs. Demographic factors such as age can influence the appearance of MN, NPB, and NBUDs. The data presented in this study are minimal. A larger sample is needed to obtain comprehensive results, especially to validate the correlation between age and the frequency of MN.

\section{Acknowledgment}

This work was financially supported by "DIPA 2016" Center for Technology of Radiation Safety and Metrology, National Nuclear Energy Agency (PTKMR-BATAN). Therefore, we are grateful for this funding and support of this research. We are also thankful to our co-workers in Cytogenetic Laboratory, PTKMR, BATAN, Jakarta; Department of Radiotherapy, dr. Soetomo General Academic Hospital, Surabaya.

\section{References}

Anbumani, S., \& Mohankumar, M. N. (2015). Nucleoplasmic bridges and tailed nuclei are signatures of radiation exposure in Oreochromis mossambicus using erythrocyte micronucleus cytome assay (EMNCA). Environmental Science and Pollution Research, 22(23), 18425-18436. https://doi.org/10.1007/s11356-015-5107-1.

Battershill, J. M., Burnett, K., \& Bull, S. (2008). Factors affecting the incidence of genotoxicity biomarkers in peripheral blood lymphocytes: Impact on design of biomonitoring studies. Mutagenesis, 23(6), 423-437. https://doi.org/10.1093/mutage/gen040.

Bonassi, S., El-Zein, R., Bolognesi, C., \& Fenech, M. (2011). Micronuclei frequency in peripheral blood lymphocytes and cancer risk: Evidence from human studies. Mutagenesis, 26(1), 93-100. https://doi.org/10.1093/mutage/geq075.

Fenech, M., Kirsch-Volders, M., Natarajan, A. T., Surralles, J., Crott, J. W., Parry, J., Norppa, H., Eastmond, D. A., Tucker, J. D., \& Thomas, P. (2011). Molecular mechanisms of micronucleus, nucleoplasmic bridge and nuclear bud formation in mammalian and human cells. Mutagenesis, 26(1), 125-132. https://doi.org/10.1093/mutage/geq052.

Fenech, M., \& Bonassi, S. (2011). The effect of age, gender, diet and lifestyle on DNA damage measured using micronucleus frequency in human peripheral blood lymphocytes. Mutagenesis, 26(1), 43-49. https://doi.org/10.1093/mutage/geq050.

Fenecht, M., Denham, J., Francis, W., Hospital, M., Wales, N. S., Hospital, R. A., et al. (1990). Micronuclei in cytokinesis-blocked lymphocytes of cancer patients following fractionated partial-body radiotherapy We applied the cytokinesis-block micronucleus assay to measure chromosome damage in lymphocytes of 11 cancer patients undergoing fractionate. International Journal of Radiation Biology, 57(2), 373-383.

Gashi, G., Mahovlić, V., Manxhuka-Kerliu, S., Podrimaj-Bytyqi, A., Gashi, L., \& Elezaj, I. R. (2018). The association between micronucleus, nucleoplasmic bridges, and nuclear buds frequency and the degree of uterine cervical lesions. Biomarkers, 23(4), 364-372. https://doi.org/10.1080/1354750X.2018.1428828.

IAEA. (2011). Cytogenetic Dosimetry: Applications in Preparedness for and Response to Radiation Emergencies.

Iarmarcovai, G., Ceppi, M., Botta, A., Orsière, T., \& Bonassi, S. (2008). Micronuclei frequency in peripheral blood lymphocytes of cancer patients: A meta-analysis. Mutation Research - Reviews in Mutation Research, 659(3), 274-283. https://doi.org/10.1016/j.mrrev.2008.05.006.

Keen-Kim, D., Nooraie, F., \& Nangesh Rao, P. (2008). Cytogenetic biomarkers for human cancer. Frontiers in Bioscience, 13, $5928-5949$. 
Lindberg, H. K., Wang, X., Järventaus, H., Falck, G. C. M., Norppa, H., \& Fenech, M. (2007). Origin of nuclear buds and micronuclei in normal and folate-deprived human lymphocytes. Mutation Research - Fundamental and Molecular Mechanisms of Mutagenesis, 617(1-2), 33-45. https://doi.org/10.1016/j.mrfmmm.2006.12.002.

Lusiyanti, Y., Alatas, Z., Syaifudin, M., \& Purnami, S. (2016). Establishment of a dose-response curve for X-ray-induced micronuclei in human lymphocytes. Genome Integrity, 7(7), 1-4.

Lusiyanti, Y., Kurnia, I., Suvifan, V. A., Sardini, S., Purnami, S., \& Rahajeng, N. (2017). Evaluation of chromosomal aberrations and micronuclei in medical workers chronically exposed to low dose ionizing radiation. Biosaintifika, 9(3), 585-591. https://doi.org/10.15294/biosaintifika.v9i3.12382.

Narendran, N., Luzhna, L., \& Kovalchuk, O. (2019). Sex difference of radiation response in occupational and accidental exposure. Frontiers in Genetics, 10(MAY), 1-11. https://doi.org/10.3389/fgene.2019.00260.

Özdal, A., Erselcan, T., Özdemir, Ö., Silov, G., Erdoğan, Z., \& Turhal, Ö. (2016). Micronucleus frequencies in groups receiving external or internal radiation. Indian Journal of Nuclear Medicine, 31(3), 179-184. https://doi.org/10.4103/0972- 3919.183621.

Palyvoda, O., Polańska, J., Wygoda, A., \& Rzeszowska-Wolny, J. (2003). DNA damage and repair in lymphocytes of normal individuals and cancer patients: Studies by the comet assay and micronucleus tests. Acta Biochimica Polonica, 50(1), 181- 190. https://doi.org/10.18388/abp.2003_3725.

Pardini, B., Viberti, C., Naccarati, A., Allione, A., Oderda, M., Critelli, R., Preto, M., Zijno, A., Cucchiarale, G., Gontero, P., Vineis, P., Sacerdote, C., \& Matullo, G. (2017). Increased micronucleus frequency in peripheral blood lymphocytes predicts the risk of bladder cancer. British Journal of Cancer, 116(2), 202-210. https://doi.org/10.1038/bjc.2016.411.

Sommer, S., Buraczewska, I., \& Kruszewski, M. (2020). Micronucleus assay: The state of art, and future directions. International Journal of Molecular Sciences, 21(4), 7-9. https://doi.org/10.3390/ijms21041534.

Ye, C. J., Sharpe, Z., Alemara, S., Mackenzie, S., Liu, G., Abdallah, B., Horne, S., Regan, S., \& Heng, H. H. (2019). Micronuclei and genome chaos: Changing the system inheritance. Genes, 10(5), 1-21. https://doi.org/10.3390/genes10050366. 